Original Research

\title{
Perancangan Mainan Puzzle untuk Media Belajar dan Media Terapi Motorik Halus bagi Anak Autis
}

\author{
Pande Putu Darmayasa ${ }^{1 *}$, Markus Hartono ${ }^{1}$, I Made Ronyastra ${ }^{1}$ \\ ${ }^{1}$ Fakultas Teknik, Universitas Surabaya, Raya Kalirungkut Surabaya-Indonesia 60293 \\ *corresponding author: pandedarma2014@gmail.com
}

\begin{abstract}
An autistic child is a child who has a functional brain disruption, causing the child to have difficulty in carrying out social interactions with his/her environment because they live "in their own world". Even though children with autism have such disabilities and limitations, the characteristics of children who like to play and explore, thus, games become one of the most effective learning and therapeutic methods for them. There are limited number of puzzle games today that address the needs of autistic children which can support their learning process and serve as therapy for fine motoric skills in children. A puzzle game was designed to be used as a medium for learning and at the same time as a way of therapy of fine motorc skills for autistic children. An initial survey was conducted in the form of questionnaires and interviews with therapists and teachers who handle autistic children in two autistic schools in Surabaya, Indonesia. The results of needs metrics were used as a basis for developing the concepts of this product. The concept generation, concept selection, and concept testing were used. After selecting the definitive concept, calculations were made to compute material costs, making product prototypes, economic analysis, and product testing. The product testing was carried out with children with early or basic autism using a prototype of the product that resembled the original. Through product testing, it was found that this product is in accordance with the needs of children with autism.
\end{abstract}

Keywords: autistic children, puzzle, motoric skills therapy, need metric, product concept

\begin{abstract}
Abstrak- Anak autis merupakan anak yang mempunyai gangguan pada fungsi otak sehingga menyebabkan anak tersebut kesulitan dalam mengadakan interaksi sosial dengan lingkungannya dan seolah-olah hidup dalam dunianya sendiri. Meskipun anak dengan autis memiliki gangguan dan ketidakmampuan sedemikian rupa, karakteristik anak yang senang bermain dan berekspolasi tidak dapat hilang begitu saja sehingga permainan menjadi salah satu metode pembelajaran dan terapi yang efektif untuk mereka. Tidak banyak permainan puzzle yang ada saat ini sesuai dengan kebutuhan anak autis yang dapat menunjang proses belajar dan terapi untuk motorik halus pada anak. Oleh karena itu dirancanglah sebuah permainan puzzle yang dapat digunakan sebagai media belajar dan media terapi motorik halus bagi anak autis. Pengumpulan data dilakukan melalui survai survai awal berupa kuesioner dan wawancara dengan terapis atau pengajar yang menangani anak autis di dua sekolah autis yang berada di Surabaya. Hasil need metric digunakan sebagai dasar dalam pengembangan konsep produk ini. Pemilihan konsep produk dilakukan melalui tiga tahap, yaitu Concept Generation, Concept selection, dan Concept testing. Setelah diperoleh satu konsep, maka dilakukan perhitungan untuk biaya material, pembuatan prototype produk, analisa ekonomi, dan pengujian produk. Pengujian produk dilakukan pada anak autis tingkat awal atau dasar dengan menggunakan prototype produk yang menyerupai aslinya. Hasil uji-coba menunjukkan produk ini sudah sesuai dengan kebutuhan anak autis, baik dari segi keamanan, estetika, maupun kegunaannya. Responden menyarankan agar harga produk bisa dibuat lebih ekonomis.
\end{abstract}

Kata kunci: anak autis, puzzle, terapi keterampilan motorik, need metric, konsep produk

\section{PENDAHULUAN}

Beberapa permasalahan yang secara umum terdapat pada anak dengan gangguan autis adalah pada aspek sosial dan komunikasi yang sangat kurang atau lambat serta perilaku yang repetitif atau pengulangan dan keadaan ini dapat kita amati pada anak seperti kekurang mampuan anak untuk menjalin interaksi sosial yang timbal balik secara baik dan memadai, kurang kontak mata, ekspresi wajah yang kurang ceria serta gerak-gerik anggota tubuh yang kurang tertuju, tidak dapat bermain dengan teman sebaya sehingga terlihat sendiri saja atau cenderung menjadi penyendiri bahkan tidak dapat berempati atau merasakan apa yang dirasakan orang lain (Munaroh, 2010).

Anak dengan gangguan autis sudah selayaknya mendapatkan perhatian lebih dari lingkungan sekitar, terutama keluarganya karena anak autis juga akan mengalami perkembangan dan pertumbuhan seperti anak normal lainnya dan memerlukan stimulus dari lingkungan sekitarnya. Tentu beberapa aspek perkembangan yang akan dilalui oleh anak autis tidak akan sama dengan perkembangan pada anak normal dan khususnya disini perkembangan motoriknya pasti terhambat.

Anak autis tidak dapat didefinisikan sebagai anak yang tidak memiliki kelebihan. Namun mereka hanya memiliki metode belajar yang berbeda dari anak normal. Dalam dunia 
anak-anak kata bermain adalah suatu hal yang tidak dapat dipisahkan. Karakteristik utama dari seorang anak adalah kesukaan mereka terhadap kegiatan bermain. Meskipun anak dengan autis memiliki gangguan dan ketidakmampuan sedemikian rupa, karakteristik anak yang senang bermain dan berekspolasi tidak dapat hilang begitu saja sehingga permainan menjadi salah satu metode pembelajaran dan terapi yang efektif untuk mereka.

Banyak permainan yang dapat digunakan untuk media terapi pada anak autis, salah satunya yaitu puzzle. Puzzle adalah sebuah permainan puzzle yang memiliki dimensi dan berbentuk nyata sesuai dengan bentuk yang bisa dikenali dengan mudah oleh anak autis. Permainan puzzle akan membuat peserta didik menjadi termotivasi untuk mengikuti pembelajaran dengan merangkai potongan puzzle secara tepat dan cepat. Puzzle dapat merangsang perkembangan motorik halus anak autis, puzzle juga dapat digunakan untuk melatih daya ingat, daya nalar, kreatifitas dan fokus untuk anak autis. Selain itu dengan puzzle anak autis diperkenalkan dengan warna, bentuk dan rupa dari benda-benda yang ada di sekitarnya (Srianis, Suarni, \& Ujiati, 2014).

Namun pada kenyataannya tidak banyak permainan puzzle yang ada saat ini dapat mendukung pembelajaran anak autis. Permainan puzzle yang ada saat ini merupakan puzzle yang umum diberikan untuk anak normal sehingga puzzle tersebut tidak sesuai dengan kebutuhan dari anak autis. Sebagai contoh yaitu mainan puzzle yang ada saat ini tidak dapat digunakan sebagai media terapi motorik halus untuk anak autis, padahal itu merupakan salah satu kebutuhan anak autis untuk menunjang perkembangan motoriknya. Oleh karena itu, penelitian ini merancang sebuah mainan puzzle yang dapat digunakan sebagai media belajar dan dapat digunakan sebagai media terapi untuk merangsang perkembangan motorik halus bagi anak autis.

\section{METODE}

Permasalahan yang ada saat ini, pada kenyataannya tidak banyak permainan puzzle yang sesuai dengan kebutuhan anak autis dan dapat digunakan untuk mendukung pembelajaran dan terapi motorik halus bagi anak autis. Oleh karena itu, untuk mengatasi hal tersebut dirancanglah sebuah permainan puzzle yang sesuai dengan kebutuhan dan dapat digunakan untuk media belajar dan terapi untuk anak autis. Untuk mengetahui kebutuhankebutuhan anak autis yang akan dijadikan dasar dalam proses perancangan produk agar sesuai dengan kebutuhan penggunanya, maka pengumpulan data dilakukan dengan tiga cara yaitu, observasi dengan melakukan wawancara, kuesioner, dan pengamatan. Pengamatan dilakukan di dua sekolah yang terletak di Kota Surabaya yaitu di Cakra Autisme Center dan AGCA Center.

Setelah diketahui apa saja kebutuhan perancangan produk untuk anak autis, maka digunakan tabel need metric dan perhitungan House of Quality (HOQ) untuk memenuhi kebutuhan tersebut dan digunakan sebagai dasar pengembangan konsep produk ini.

Pemilihan konsep melewati tiga tahap, yaitu concept generation, concept selection, dan concept testing (Ulrich, Eppinger, \& Yang, 2020). Concept generation untuk melihat kombinasi konsep yang diperoleh dari hasil analisis perhitungan HOQ (Mao \& Peña-mora, 2019). Concept selection bertujuan untuk memilih satu konsep akhir produk yang akan dirancang dari berbagai alternatif konsep yang ada. Concept testing bertujuan untuk mengetahui apakah konsep akhir produk ini sudah sesuai dengan kebutuhan anak autis. Setelah diperoleh konsep akhir dari produk ini, maka dilanjutkan ke tahap selanjutnya yaitu product architecture yang bertujuan untuk mengetahui komponen apa saja yang terdapat dalam produk mainan ini dengan lebih detail.

Tahap selanjutnya yaitu indutrial design yang bertujuan untuk mengoptimalkan fungsi dan nilai dari produk agar nantinya dapat diterima oleh konsumen. Selanjutnya adalah tahap design for manufacturing (DFM) yang bertujuan untuk mengetahui jumlah komponen yang perlu dibuat sehingga memudahkan proses manufacturing untuk memperkirakan berapa banyak bahan yang diperlukan secara lebih detail pada bill of material (BOM) dan nantinya mempermudah perhitungan biaya-biaya yang ada dianalisis ekonomi produk. Sesudah itu 
dirancanglah prototype produk mainan ini yang kemudian dilakukan product testing untuk mengetahui apa saja kekurangan yang perlu diperbaiki dalam prototype.

HASIL

Melalui pengumpulan data yang dilakukan dengan cara wawancara, kuesioner, dan pengamatan maka diperolehlah hasil mengenai apa saja kebutuhan anak autis yang menjadi dasar dalam perancangan produk. Dari kuesioner itu juga diperoleh informasi tingkat kepentingan dari kebutuhan yang perlu diperhatikan. Berikut ini tabel mengenai kebutuhan yang sudah diurutkan dari tingkat yang paling penting.

Tabel 1

Tingkat Kepentingan Kebutuhan Anak Autis

\begin{tabular}{|c|c|c|c|c|c|c|c|c|c|}
\hline \multirow[b]{2}{*}{ Kebutuhan } & \multicolumn{5}{|c|}{ Tingkat Kepentingan } & \multirow[b]{2}{*}{ Total } & \multirow[b]{2}{*}{ Mean } & \multirow[b]{2}{*}{ Bobot } & \multirow[b]{2}{*}{ Rank } \\
\hline & 1 & $?$ & 3 & 4 & 5 & & & & \\
\hline Aman & 0 & 0 & 1 & 0 & 29 & 148 & 4.93 & $12.90 \%$ & I \\
\hline Jelas fungsinya & 0 & 0 & 0 & 6 & 24 & 144 & 4.80 & $12.55 \%$ & II \\
\hline Prosedur mudah diikuti & 0 & 0 & 1 & 14 & 15 & 134 & 4.47 & $11.68 \%$ & III \\
\hline Tahan lama & 0 & 1 & 2 & 9 & 18 & 134 & 4.47 & $11.68 \%$ & IV \\
\hline Bentuk & 0 & 2 & 5 & 8 & 15 & 126 & 4.20 & $10.99 \%$ & V \\
\hline Warna & 0 & 3 & 4 & 8 & 15 & 125 & 4.17 & $10.90 \%$ & VI \\
\hline Mudah dibawa & 0 & 2 & 6 & 12 & 10 & 120 & 4.00 & $10.46 \%$ & VII \\
\hline Dimensi ukuran & 0 & 3 & 13 & 3 & 11 & 112 & 3.73 & $9.76 \%$ & VIII \\
\hline Mudah disimpan & 3 & 4 & 6 & 10 & 7 & 104 & 3.47 & $9.07 \%$ & IX \\
\hline Total & & & & & & 1147 & 38.23 & $100.00 \%$ & \\
\hline
\end{tabular}

Setelah diketahui apa saja kebutuhan dari anak autis maka selanjutnya dicari apa saja pemenuhan dari kebutuhan tersebut dan seberapa besar pengaruh dari pemenuhan tersebut terhadap kebutuhan anak autis menggunakan need metric. Hubungan kebutuhan dengan pemenuhan tersebut dibuat dalam bentuk tabel yang kemudian dilihat pemenuhan mana yang memiliki pengaruh paling besar. Pada Tabel 2 ditunjukkan need metric tentang bagaimana keterkaitan kepentingan antara kebutuhan anak autis dengan aspek teknis perancangan produk.

Dari Tabel 2 tersebut diperoleh tiga pemenuhan yang memiliki bobot tertinggi dan bernilai lebih dari rata-rata bobot yaitu bentuk, material, dan ukuran. Ketiga pemenuhan ini kemudian digunakan sebagai dasar dalam pengembangan konsep produk. Pengembangan konsep produk dilakukan melalui 3 tahap. Tahap pertama adalah concept generation, yang merupakan kombinasi dari ketiga pemenuhan tersebut dan diperoleh 6 alternatif konsep dari produk (lihat Tabel 3). 


\section{Tabel 2}

Keterkaitan Kepentingan Antara Kebutuhan Anak Autis Dengan Aspek Teknis Perancangan Produk

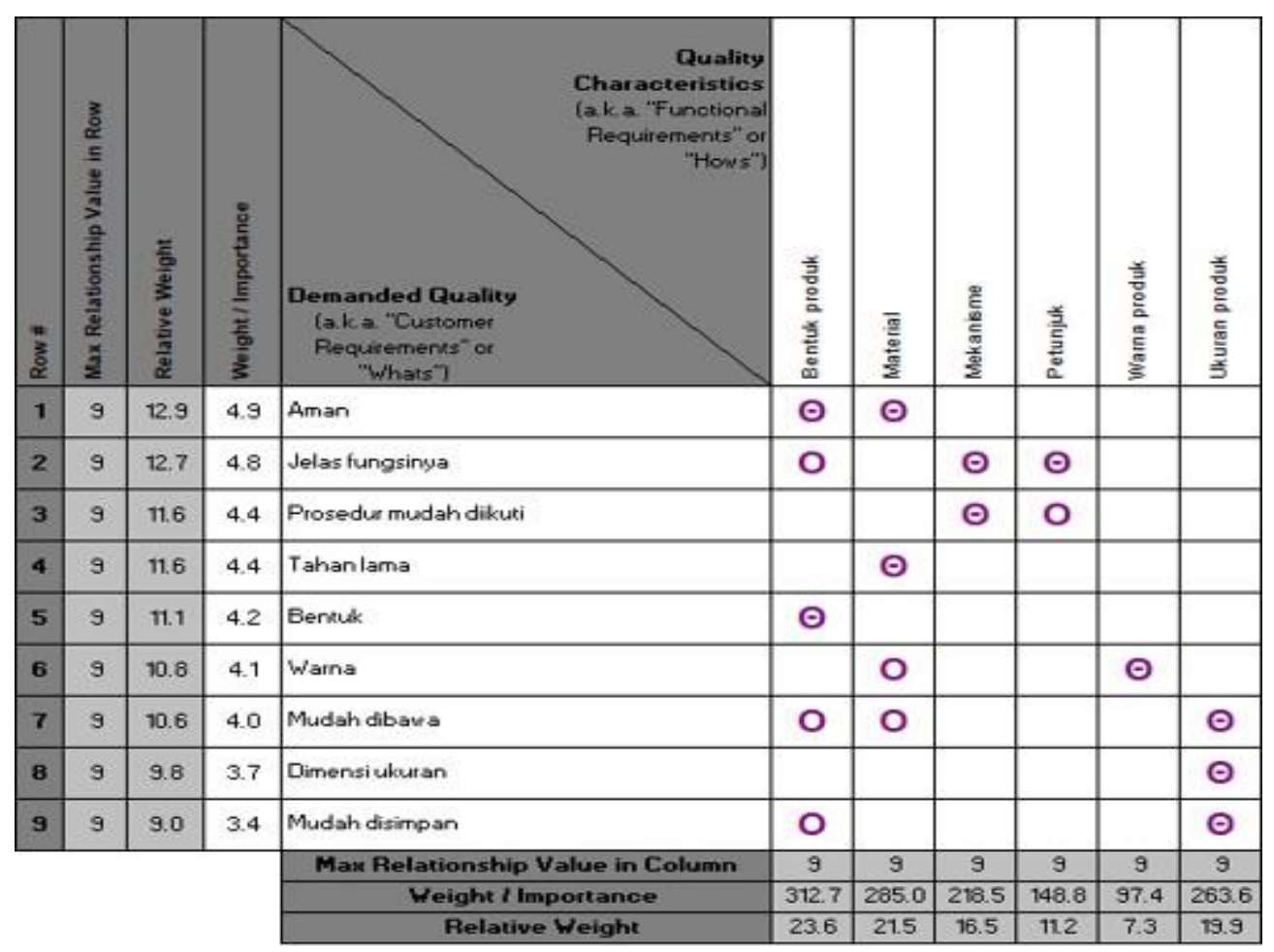

Tabel 3

Tabel Kombinasi

\begin{tabular}{cccc}
\hline \multicolumn{1}{c}{ Bentuk produk } & Material & Ukuran produk & $\begin{array}{c}\text { Jumlah } \\
\text { alternatif }\end{array}$ \\
\hline $\begin{array}{l}\text { Setengah lingkaran } \\
\text { dengan penutup bulat }\end{array}$ & Kayu & $\begin{array}{l}\text { Ukuran produk menyesuaikan dengan data } \\
\text { antropometri anak Indonesia usia 6-9 tahun }\end{array}$ & \\
$\begin{array}{l}\text { Setengah lingkaran } \\
\text { dengan penutup datar }\end{array}$ & Plastik & & \\
2 & 2 & 1 & 6 alternatif \\
\hline
\end{tabular}

Berdasarkan Tabel 3 tersebut diperoleh enam alternatif konsep. Keenam alternatif konsep tersebut dieliminasi pada tahap concept selection, sehingga diperoleh satu konsep akhir produk yang akan dirancang. Berikut merupakan gambar 3D konsep akhir produk. Dimensi produk menggunakan data antropometri yang diadopsi dari Hartono (2018). 


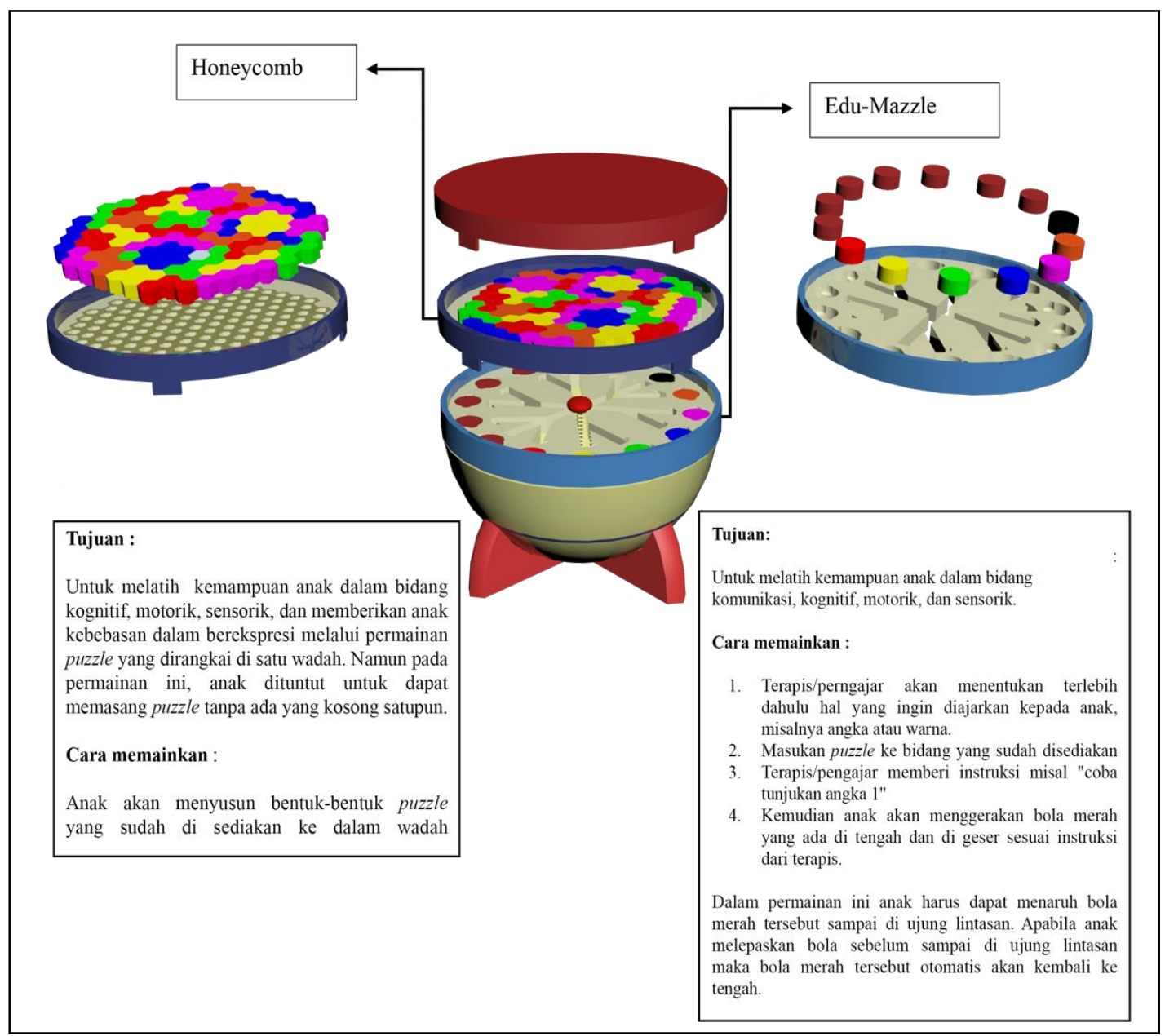

Gambar 1. Konsep akhir produk.

Produk mainan ini diberi nama Edufunzle (Education Funny Puzzle). Kemudian setelah diperoleh satu konsep akhir produk, maka dilanjutkan ke tahap concept testing untuk melihat apakah konsep produk sudah sesuai dengan kebutuhan anak autis. Apabila konsep tersebut sudah sesuai dengan kebutuhan anak autis, selanjutnya dirancang prototype produk sesuai dengan konsep akhir.

\section{DISKUSI}

Produk mainan ini diberi nama Edufunzle atau Education Funny Puzzle yang berarti permainan puzzle yang menyenangkan dan mendidik. Sebelum merancang prototype Edufunzle, berikut ini beberapa tahap yang perlu dilakukan: (1) product architectur, pada bagian ini komponen fisik dasar produk diuraikan menjadi lebih detail lagi untuk mengetahui komponen-komponen apa saja yang ada dalam perancangan produk; (2) industrial design, bagian ini memperhitungkan aspek estetika dan ergonomi produk untuk menciptakan dan mengembangkan konsep dan spesifikasi yang akan mengoptimalkan fungsi, nilai, dan penampilan produk dan sistem untuk keuntungan penggunaan dan pembuat produk; (3) design for manufacturing yang bertujuan menyederhanakan, mengoptimalkan, dan menyempurnakan design produk agar tercipta produk yang lebih baik dengan biaya rendah. Salah satu langkah untuk melakukan design for manufacturing adalah dengan membuat bill of material yang bertujuan mengetahui komponen apa saja yang perlu dibuat dan jumlah dari komponen tersebut, sehingga dapat memperhitungkan berapa banyak bahan yang harus digunakan dan berapa biaya yang harus dikeluarkan (lihat Tabel 4). 
Tabel 4

Material dan Harga Dalam Perancangan Edufunzle

\begin{tabular}{llcrr}
\hline No & Bahan/Material pendukung & Qty & Harga satuan (Rp) & Total harga yang dipakai (Rp) \\
\hline 1 & Jasa laser cut 60 menit & 60 & $\mathrm{Rp} 1.500,00$. & $\mathrm{Rp} 90.000,00$. \\
2 & Cat warna & 3 & $\mathrm{Rp} 65.000,00$. & $\mathrm{Rp} 195.000,00$. \\
3 & Epoxcy & 1 & $\mathrm{Rp} 65.000,00$. & $\mathrm{Rp} 65.000,00$. \\
4 & Dempul & 1 & $\mathrm{Rp} 40.000,00$. & $\mathrm{Rp} 40.000,00$. \\
5 & Lem presto & 1 & $\mathrm{Rp} 35.000,00$. & $\mathrm{Rp} 35.000,00$. \\
6 & MDF 1/2 lembar & 1 & $\mathrm{Rp} 100.000,00$. & $\mathrm{Rp} 100.000,00$. \\
7 & Kayu akasia & 1 & $\mathrm{Rp} 800.000,00$. & $\mathrm{Rp} 800.000,00$. \\
8 & Jasa operator & 1 & $\mathrm{Rp} 1000.000,00$. & $\mathrm{Rp} 1000.000,00$. \\
& Total & & $\mathrm{Rp2.325.000,00}$ \\
\hline
\end{tabular}

Setelah dilakukan perhitungan mengenai material dan berapa biaya yang dikeluarkan, selanjutnya dilalukan proses perancangan prototype Edufunzle dan dilakukan perhitungan harga jual untuk pasar. Tabel 5 berikut ini merupakan tabel perhitungannya.

Tabel 5

Perhitungan Harga Jual Produk

\begin{tabular}{|c|c|}
\hline \multicolumn{2}{|c|}{ Perhitungan harga pembuatan produk (HPP) } \\
\hline Keterangan & Total Biaya (Rp) \\
\hline Biaya bahan baku & Rp1.235.000,00 \\
\hline Biaya tenaga kerja & Rp1.090.000,00. \\
\hline Total HPP & Rp2.325.000,00. \\
\hline \multicolumn{2}{|c|}{ Perhitungan Harga Jual Pembuatan Produk } \\
\hline Total HPP & Keuntungan (\%) \\
\hline Rp2.325.000,00. & 30 \\
\hline Total harga jual & Rp3.000.000,00. \\
\hline
\end{tabular}

Perhitungan tersebut merupakan perhitungan untuk harga jual dua unit produk Edufunzle, sehingga untuk satu unit produk Edufunzle akan dijual dengan harga Rp1.500.000,00. Apabila dibandingkan dengan produk mainan untuk anak autis lainnya, produk ini tergolong masih mahal dikarenakan bahan yang digunakan merupakan bahan kayu dan juga dalam proses pembuatannya hanya dua unit saja.

Tahap selanjutnya dilakukan uji coba prototype Edufunzle terhadap anak autis tingkat awal dengan ukuran tubuh besar dan kecil. Uji coba terhadap dua anak yang mempunyai ukuran tubuh yang berbeda ini bertujuan untuk melihat apakah produk ini sudah ergonomi dan dapat digunakan oleh anak yang mempunyai ukuran tubuh besar maupun kecil.

Edufunzle terdiri atas dua permainan yang memiliki mekanisme yang berbeda dan dimainkan dengan cara bertahap. Permainan pertama diberi nama Edu-Mazzle atau Education Maze Puzzle yang berarti puzzle labirin yang mendidik. Melalui permainan Edu-Mazzle anak autis akan belajar mengenal angka dan warna. Selain itu juga dapat menstimulus motorik halus pada tangan anak dengan menggerakkan benda yang dikaitkan dengan per. Kemampuan anak dalam bidang komunikasi juga dilatih melalui intruksi yang diberikan oleh pengajar/terapis.

Selanjutnya, setelah anak autis sudah dapat memainkan mainan pertama dengan baik maka akan dilanjutnya ke permainan kedua. Permaian kedua diberi nama Honeycomb. Mainan kedua ini bertujuan untuk meningkatkan kekuatan motorik halus pada tangan anak dan memastikan perkembangan motorik halus pada jari anak sudah meningkat. Hal ini dilakukan dengan media puzzle dimana anak autis akan merangkai kepingan-kepingan puzzle yang memiliki bentuk yang berbeda-beda ke dalam bidang Honeycomb yang disediakan. Pada permainan ini motorik halus pada tangan anak autis harus cukup kuat untuk merangkai semua 
puzzle menjadi satu bentuk yang utuh karena jika tidak cukup kuat maka puzzle yang tersusun tersebut tidak dapat tersusun secara utuh karena motorik yang masih lemah membuat anak autis tidak dapat menggenggam kepingan puzzle dengan lama. Selain untuk meningkatkan kekuatan motorik halus pada anak, permainan kedua ini juga dapat digunakan melatih kemampuan berpikir anak dari aspek kreatifitas.

Untuk mengetahui apakah Edufunzle sudah memenuhi kebutuhan anak autis atau belum, maka dilakukan pengumpulan data dengan menggunakan kuesioner yang diberikan kepada pengajar/terapis (10 orang) yang mendampingi anak-anak tersebut. Hasil kuesioner ditunjukkan pada Tabel 6.

Berdasarkan kuesioner pengujian produk Edufunzle dapat diketahui bahwa seluruh responden setuju bahwa Edufunzle dapat digunakan sebagai media belajar dan media terapi motorik halus bagi anak autis. Dari kuesioner tersebut juga diketahui bahwa Edufunzle sudah memenuhi kebutuhan anak autis dengan persentase jawaban responden di atas $50 \%$ yaitu: aman untuk digunakan, fungsi mainan jelas, prosedur mudah diikuti, tahan lama, bentuk mainan unik, warna yang digunakan menarik, mudah dibawa, dimensi ukuran sesuai untuk anak, dan mudah disimpan. Namun diperoleh satu jawaban dengan persentase di bawah $50 \%$, yaitu ketersediaan responden dalam membeli produk Edufunzle dengan harga Rp1.500.000,00. Alasan responden tidak bersedia membeli dengan harga tersebut dikarenakan harga dianggap terlalu mahal dan kurang ekonomis sehingga responden berharap agar harga produk Edufunzle bisa lebih ekonomis. Beberapa hal yang menyebabkan produk Edufunzle mahal dikarenakan material yang digunakan adalah material kayu. Selain itu responden juga memberikan saran agar mencoba untuk memproduksi produk ini dengan bahan selain kayu seperti plastik.

Tabel 6

Hasil Kuesioner Pengujian Produk Edufunzle

\begin{tabular}{lccc}
\hline \multicolumn{1}{c}{ Pertanyaan } & Pilihan & Jumlah & \% \\
jawaban & & $\mathbf{1 0 0 \%}$ \\
\hline Berdasarkan pengujian yang telah dilakukan, & Ya & 10 & $\mathbf{0 \%}$ \\
apakah produk ini dapat digunakan sebagai media & Tidak & 0 & $\mathbf{1 0 0 \%}$ \\
belajar dan media terapi motorik halus & & & $\mathbf{1 0 0 \%}$ \\
bagi anak autis? & Total & $\mathbf{1 0}$ & $\mathbf{0 \%}$ \\
Mainan aman digunakan untuk anak autis & Ya & 10 & $\mathbf{1 0 0 \%}$ \\
& Tidak & 0 & $\mathbf{9 0 \%}$ \\
Fungsi mainan jelas & Total & $\mathbf{1 0}$ & $\mathbf{1 0 \%}$ \\
& Ya & 9 & $\mathbf{1 0 0 \%}$ \\
Prosedur mudah diikuti & Tidak & 1 & $\mathbf{8 0 \%}$ \\
& Total & $\mathbf{1 0}$ & $\mathbf{2 0 \%}$ \\
Tahan lama & Ya & 8 & $\mathbf{1 0 0 \%}$ \\
& Tidak & 2 & $\mathbf{1 0 0 \%}$
\end{tabular}




\begin{tabular}{lcccc} 
& \multicolumn{3}{c}{ https:/doi.org/10.24123/saintek.v1i2.2978 } \\
\hline \multirow{2}{*}{ Mudah dibawa } & Total & $\mathbf{1 0}$ & $\mathbf{1 0 0 \%}$ & $\mathbf{6 0 \%}$ \\
& Ya & 6 & $\mathbf{4 0 \%}$ \\
Dimensi ukuran sesuai untuk anak & Tidak & 4 & $\mathbf{1 0 0 \%}$ \\
& Total & $\mathbf{1 0}$ & $\mathbf{8 0 \%}$ \\
Mudah disimpan & Ya & 8 & $\mathbf{2 0 \%}$ \\
& Tidak & 2 & $\mathbf{1 0 0 \%}$ \\
& Total & $\mathbf{1 0}$ & $\mathbf{9 0 \%}$ \\
Apabila produk ini dijual dengan harga Rp1.500.000,00, & Ya & 9 & $\mathbf{9 0 \%}$ \\
apakah anda bersedia membelinya & Tidak & 1 & $\mathbf{1 0 0 \%}$ \\
& Total & $\mathbf{1 0}$ & $\mathbf{4 0 \%}$ \\
& Tidak & 6 & $\mathbf{6 0 \%}$ \\
\hline
\end{tabular}

\section{SIMPULAN}

Penelitian ini dilakukan dengan tujuan dapat merancang permainan puzzle yang dapat mendukung pembelajaran anak dan dapat digunakan sebagai media terapi motorik halus bagi anak autis. Hasil penelitian dan diskusi menunjukkan bahwa Edufunzle adalah permainan yang sesuai dengan kebutuhan pembelajaran anak autis. Diperlukan bahan yang lebih ekonomis agar Edufunzle dapat dijual dengan harga yang lebih ekonomis pula.

\section{PUSTAKA ACUAN}

Hartono, M 2018, 'Indonesian anthropometry update for special populations incorporating Drillis and Contini revisited', International Journal of Industrial Ergonomics, Vol. 64, pp. 89-101, https://doi.org/10.1016/j.ergon.2018.01.004

Mao, Q, Li, N, \& Peña-mora, F, 2019, 'Quality function deployment-based framework for improving the resilience of critical infrastructure systems', International Journal of Critical Infrastructure Protection, Vol. 26, pp. 100-304. https://doi.org/10.1016/j.ijcip.2019.100304

Muniroh, SM 2010, 'Dinamika resiliensi orang tua anak autis', Jurnal Penelitian, Vol. 7, No. 2, hlm. 1-11.

Srianis, K, Suarni, NK, \& Ujianti, PR 2014, 'Penerapan metode bermain puzzle geometri untuk meningkatkan perkembangan kognitif anak dalam mengenal bentuk', Jurnal Pendidikan Usia Dini Undhiksa, Vol. 2, No. 1, hlm. -

Ulrich, KT, Eppinger, SD, Yang, MC 2020, Product design and development, $7^{\text {th }}$ Edition, McGraw-Hill Education. 